\title{
Salacak'tan Kartal'a Kadar Plâj Sularının Mikrobi- yolojik Analizleri Üzerinde Araştırmalar
}

The Microbiological Analysis of the Sea Water which were belong to the Beaches from Salacak to Kartal

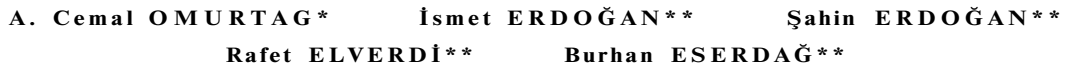

Halka açık yüzme havuzları ile evlerde yüzme amacı ile kullanılandan özel havuzların suları; gerek kullanılan suyun orijinine bağlı olarak ve gerekse bu suya girenler tarafından sağlık için zararlı mikroorganizmalar ile kontamine edilmektedir. Hijiyenik anlamda pürifiye edilemeyen bu yüzme havuzlarının suları Otitis media, Gastroenteritis, Dermatitis, Conjunctivitis ve solunum yolu enfeksiyonlar1na sebep olmaktadir.

GRAY (4); İngiltere Halk Sağlığı Örgütünce kabul edilen standardın; "Yüzme havuzu suyundan alman 100 c. c. numunede Coliform grubu mikroorganizma bulunmayacak ve bu sudan alınan numunelerin \% 75 inin 1 c. c. sinde, Total bakteri sayısının 10 dan; geriye kalan numune oranının ise 100 den fazla olmayacağ 1 " kaydını taşıdı̆̆ını bildirmektedir.

Muhtelif tarihlerde YANÇ ve AYDENİ (7) tarafından İstanbul Florya; KOÇ (5) tarafından Samsun; ERDOĞAN (3) tarafindan da Pendik civarındaki plajların mikrobiyolojik analizleri yapılmıştır. Ancak bu çalışmalardan alınan sonuçlar ve araştırıcıların itibar ettikleri limitler çok toleranslı tutulmuştur. Bu neden ile tarafımızdan yapılan bu çalışmada iki amaç edinilmiştir.

Redaksiyona verildiği tarih: 29 Aralık 1976

* Mikrobiyoloji ve Besin Analizleri Kürsüsü, Eczacılık Fakültesi, Ankara Üniversitesi.

** Pendik Veteriner Kontrol ve Araştırma Enstitüsü, Istanbul. 
1- Yeterince geniş sahil şeridinden numune almak.

2 - Uygulanan metodun kapsamını geniş tutmak.

Bilindiği üzere şehrin veya banliyölerinin kanalizasyon tesislerinin, sahil sularının kirlenmesini önleyecek plân ve projeden yoksun olarak yapılmış olması veya şehirlerimiz için hijiyenik tutarlılı̆̆ plân ve projenin mevcut olmaması, ayrıca sanayi tesislerinin hemen yakınlarına yapılmasını önleyecek bir müeyyidenin uygulanmaması veyahut böyle bir müeyyidenin de bulunmayışı, toplumun sağlı̆̆ bakımından ciddî bir sakınca teşkil etmektedir. Böylece buralarda bilhassa gelişme çă̆ında olan gençlerin tabiatın sağlık kaynağı olan deniz ve güneşten birlikte istifade etmeleri esnasında, bu plajlardan muhtelif enfeksiyonları almaları büyük bir olasılık içindedir. Bu çalışma, bir ölçüde bu konuya açıklık getirebilmek için Eczacılık Fakültesi Yönetim Kurulunun 25. 6. 1975 gün ve 1156 sayılı kararma dayalı ve Tarım Bakanlığg Veteriner işleri Genel Müdürlüğünün müsaadesi ile, Pendik Bakteriyoloji Enstitüsü Müdürlüğünün verebildiği sınırlı olanak çerçevesinde yapılabilmiştir.

\section{MATERYAL ve YÖNTEM}

\section{MATERYAL}

Tablo (1) deki numuneler; ağzı burgulu steril şişelere, anında alkol ile yıkanmış el ile denizin sathına daldırılarak alınmış, içinde buz ihtiva eden piknik tipi termoslara yerleştirilmiş ve son numunelerin alınmasını müteakip 1 saat içinde işlenmek üzere lâboratuvar buzluğuna konmak suretiyle buzluktan sırası geldikçe çıkarılarak işlenmişlerdir. Numunelerin alındı̆̆ 1 tablo (1) de verilmiş olan meteorolojik durum, Meteoroloji Genel Müdürlügünden alınmıştır.

\section{YÖNTEM}

1- Petri metodu ile total bakteri sayımı :

CRUICKSHANK，DUGUID， MARMION ve SWAIN tarafından verilmiş olan metod uygulanmıştır.

\section{2- Coliform grubu bakteri sayımı:}

A- Tüpte yaklaşık Coliform sayımı: Bu deney için Mc CRADY tarafından kullanılmış olan teknik; CRUICKSHANK, DUGUID, 
MARM I ON ve SWAIN (1) tarafından aktarılmış olduğu şekilde uygulanmıştır.

B- Differensiyal Coliform deneyi: Keza bunun için de CRUICKS HANK, DUGUID, MARMION ve SWAIN (1) tarafından tavsiye edilen EIJKMAN'ın tekniği kullanılmıştır.

3- Streptococcus faecalis'in sayımı :

Bunun için REINBOLD, SWERN ve HUSSONG (6) tarafından bildirilmiş olan metod uygulanmıştır.

\section{4- Patogen olan Staphylococcus'lerin saptanması:}

Patogen olan StaphyIococcus'lerin izolasyonu için DIFCO (2) tarafından bildirilen Mannitol Salt Agar (B 30) besi yeri kullanılmiştır.

\section{5- Clost. welchii'nin saptanmast:}

Bunun için; Pendik Bakteriyoloji ve Seroloji Enstitüsü diagnostik lâboratuvarı tarafından uygulanması rutin hale gelmiş olan üretme ve izolasyon metod ve tekniği uygulanmıştır.

\begin{tabular}{|c|c|c|c|c|c|}
\hline & Plaj ismi & $\begin{array}{c}\begin{array}{c}\text { Numuner } \\
\text { gün }\end{array} \\
\end{array}$ & $\begin{array}{l}\text { n alındığı } \\
\text { saat } \\
\text { saat }\end{array}$ & $\begin{array}{c}\text { Göztepe Meteo- } \\
\text { roloji istasyo- } \\
\text { nunca rüzgar } \\
\text { hızı ve yönüne } \\
\text { ait kayıtları. }\end{array}$ & $\begin{array}{l}\text { Saat } 07.00 \text { de } \\
\text { Florya'daki de- } \\
\text { niz suyu sıcak- } \\
\\
\text { lığı }\end{array}$ \\
\hline $\begin{array}{r}7 \\
8 \\
9 \\
10 \\
11 \\
12 \\
13 \\
14\end{array}$ & $\begin{array}{l}\text { Salacak } \\
\text { Moda } \\
\text { Cadde bos- } \\
\text { tan } \\
\text { Cadde bos- } \\
\text { tan } \\
\text { Suadiye } \\
\text { Plâj içi } \\
\text { havuzu } \\
\text { Bostancı } \\
\text { Bostancı hal- } \\
\text { ka açı plâj } \\
\text { Küçïk yalı } \\
\text { çamlık } \\
\text { Küçük yalı } \\
\text { Belediye } \\
\text { ideal tepe } \\
\text { Süreyya } \\
\text { Kartal kum } \\
\text { plajı } \\
\text { Havacılar } \\
\text { plajı }\end{array}$ & $\begin{array}{c}16.7975 \\
, " \\
, " \\
, \\
, \\
, \\
, " \\
23.7 .1975 \\
,, \\
, " \\
,\end{array}$ & 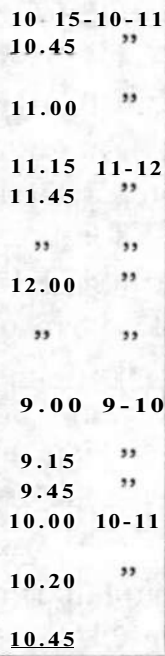 & 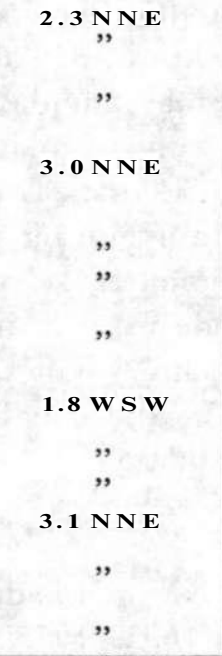 & 22.6 \\
\hline
\end{tabular}


Tablo 2: Salacak'tan Kartal'a kadar bazı plâj sularının Mikrobiyolojik Analiz Sonuçları

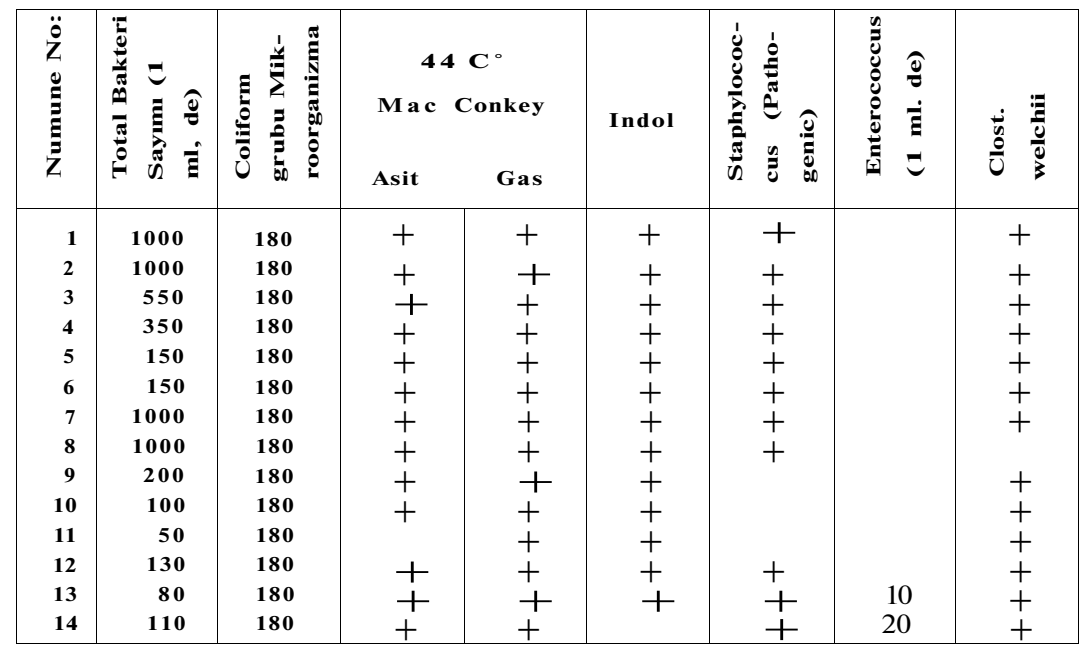

T A R T I Ș M A

Denemelerden elde edilen sonuçlara ait 2 nolu tablonun incelenmesinden de anlaşdacağı gibi, Marmara istanbul Boğazi metha$1 \mathrm{inden} \mathrm{İzmit} \mathrm{Körfezinin} \mathrm{başlanglce} \mathrm{olan} \mathrm{Pendik'e} \mathrm{kadar} \mathrm{ki} \mathrm{Anadolu}$ sahili plajlarına ait deniz sularini; yüzmek için hijiyenik olarak kabul etmek tarafimizdan tıbben imkânsiz görülmektedir. Bunun $1 \mathrm{~s} 1 \mathrm{ah} 1$

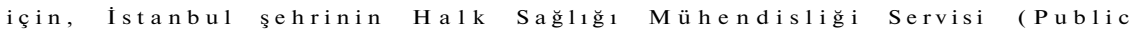
Health Engineering) adinda bir teşkilatin kurulmasi ve ayrica bu teşkilatın önerilerini uygulama alanina sokmak suretiyle sanayi artıklarının ve şehirkanalizasyon şebekesinin bir plân ve proje içinde hijiyenik kurallara uygun bir şekilde tanzimi ile hiç de ğil ise sahillerimizin insan săglı̆gına zarar vermesi önlenmelidir. Bu hijiyenik koşu-

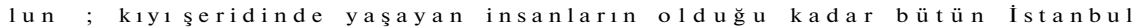
halkinın ve bu şehre yakın yaşayan toplum n sağlı̆̆ı için, özellikle y ̈̈zme mevsimi boyunca ilgili Resmi kurullarca săglanmasi kaç1nılmaz bir zorunluluktur.

Salacak'tan Kartal'a kadar plajların bulundu gu sahil şeridindeki deniz sularindan 16. 7. 1975 ve 23.7. 1975 tarihleriarasinda 14 nu- 
mune, insan sağlı̆̆1 ile ilgili olarak; Standard Petri metodu ile Total bakteri; Coliform grubu mikroorganizma ve Enterococcus'lerin sayımları ile ayrıca Staphylococcus ve Clost. welchii aranmıştır. Ayrıca Coliform grubu mikroorganizmaların $44^{\circ} \mathrm{C}$ de Mac Conkey besi yerinde Acid ve Gas teşkili ile İndol verme durumları incelenmiştir. Buralara ait sonuçlar Tablo (2) de verilmiştir.

\section{S U M MARY}

14 Sea Water samples were taken for the examination in order to detect the availability for swimming hygiene from beaches from Salacak to Kartal. For this purpose Standard Plate Count, Most Probable Number of Coliform, the number of Enterococci and Staphylococci, Clost welchii are carried out. Besides this acid and gas production of Coliform microorganisims in Mac Conkey broth at the temperature $44^{\circ} \mathrm{C}$, and also Indol production were detected. The results were given in table (2).

\section{TEŞEKK ÜR}

Araştırıcılar Meteoroloji Genel Md. Assoc. Prof. Dr. Ahmet RU MELI'ye bu araştırmada görülen meteorolojik kayıtları; Vet. İş. Genel Müd. Dr. Muzaffer Suphi ÇETİN'e Pendik Araştırma ve Kontrol Enstitüsünün diagnostik lâboratuvarlarında çalışma olanağını vermiş olmalarından ötürü şükranlarını sunarlar.

\section{LİTERAT ÜR}

1. Cruickshank, R., Duguid, J. P., Marmion, B. P. and Swain, R. H. A., Medical microbiology, Churchill livingstone, 273 (1975).

2. Difco., Difco Lab., ninth Ed. Detroid Michigan, 150 (1953).

3. Erdoğan, İ., Pendik Vet. Kont. ve Araştırma Enst. Derg. 2, 101-120 (1974).

4. Gray, R, D., J. Hygiene 62, 195 (1969).

5. Koç, F., Türk Vet. Hek. Derg. 33, 7-8 345-367 (1963).

6. Reinbold, G. W., Swern, M. and Hussong R. V., Sciene, 36, 1-6 (1953).

7. Yanç, F, ve Aydeniz, S., Mikrobiyoloji dergisi, No: 3-4, 66-73 (1969). 